\title{
Comparison of quality of life and causes of hospitalization between hemodialysis and peritoneal dialysis patients in China
}

\author{
Ai-Hua Zhang*1, Li-Tao Cheng ${ }^{1}$, Ning Zhu ${ }^{1}$, Ling-Hua Sun ${ }^{1}$ and Tao Wang ${ }^{1,2}$
}

Address: ${ }^{1}$ Division of Nephrology, Peking University Third Hospital, Beijing, People's Republic of China and ${ }^{2}$ Division of Nephrology, Peking University First Hospital, Beijing, People's Republic of China

Email: Ai-Hua Zhang* - zhangaihua0982@sina.com; Li-Tao Cheng - lt_cheng@163.com; Ning Zhu - fanminhua3641@sina.com; LingHua Sun - sunlinghuacyq@sina.com; Tao Wang - Wangt@bjmu.edu.cn

* Corresponding author

This article is available from: http://www.hqlo.com/content/5/I/49

(C) 2007 Zhang et al; licensee BioMed Central Ltd.

This is an Open Access article distributed under the terms of the Creative Commons Attribution License (http://creativecommons.org/licenses/by/2.0), which permits unrestricted use, distribution, and reproduction in any medium, provided the original work is properly cited.

\begin{abstract}
Background: Hemodialysis (HD) and peritoneal dialysis (PD) are important renal replacement treatment in end stage renal disease (ESRD), but the comparison of quality of life (QOL) and causes of hospitalisation between the two modalities in China is lacking. In the present study, we compared the two modalities in a multi-center study.

Subjects and methods: Six hundred and fifty four HD and 408 PD patients were investigated from 10 hospitals in China from Sept, 2004 to Jan, 2005. Among the HD patients, there were 360 males and 294 females with a mean age of $57.22 \pm 12.49$ years ( $18-88$ y). Among PD patients, there were 165 males and 243 females, with a mean age of $61.59 \pm 12.65$ years $(22-89 y)$. Health related 36 items short form questionnaires (SF-36) were used to assess the quality of life. Hospitalisation data were collected and analyzed.

Results: SF-36 domains of Body Pain (BP), General Health (GH), Role-Emotional (RE), Social Functioning (SF), Vitality (VT) and Mental Health (MH) were all significantly higher in the PD patients as compared to the HD patients although there was no significant difference in Physical Functioning (PF) and Role-Physical (RP) between the two groups. The two most common causes of hospitalisation in HD patients were cardiovascular disease $(39.8 \%)$ and pulmonary infection (21.3\%), while they were infectious peritonitis (47.6\%) and cardiovascular disease (31.9\%) in PD patients. The ever hospitalised patients had lower SF-36 scores in the domains of PF, BP, GH, RE, $\mathrm{SF}, \mathrm{VT}$ and $\mathrm{MH}$ as compared to those of non-hospitalised patients.

Conclusion: Our study indicated that with the current practice in China, PD patients may enjoy better quality of life than their HD counterparts. Our results also showed that the most common cause of hospitalisation was cardiovascular disease in HD patients and peritonitis in PD patients.
\end{abstract}

\section{Background}

Both hemodialysis (HD) and peritoneal dialysis (PD) are established renal replacement therapies to treat patients with end-stage renal disease (ESRD) worldwide. According to the data of Registry of Dialysis and Transplantation in 2005 in China, there were about 59,000 dialysis patients in this country and $90 \%$ of them were on HD. Although HD and PD are thought to provide similar benefits to ESRD patients, the actual large scale comparisons of quality of life (QOL) and causes of hospitalisation 
between the two modalities is currently lacking in China. In literatures, health related 36 items short form questionnaires (SF-36) were used increasingly to assess the QOL in the studies of ESRD patients [1-4]. So we employed SF-36 as a tool and investigated the QOL and causes of hospitalisation in HD and PD patients in China based on multicenter data in the present study.

\section{Subjects and Methods Data collection}

Demographic and clinical data of $661 \mathrm{HD}$ patients and 412 PD patients were derived from 10 big hospitals located in different cities in China from Sept, 2004 to Jan, 2005. Demographic information and clinical history were collected through review of medical records and selfreported SF-36 questionnaires. We categorized sociodemographic variables as follows: age, currently marriage status (yes/no), employment status (yes/no). Comorbidity was assessed by using Charlson Cormobidity Index, with higher score reflecting increased severity of disease [58].

\section{SF-36 questionnaire}

The SF-36 questionnaires were the main tool to assess QOL in dialysis patients[1-4]. The SF-36 was finally evaluated in eight domains: Physical Functioning (PF,10 items), Role-Physical (RP,4 items), Body Pain (BP,2 items), General Health (GH,5 items), Role-Emotional
(RE,3 items), Social Functioning (SF,2 items), Vitality (VT,4 items) and Mental Health (MH, 5 items). The score for each domain range from 0 to 100 with higher scores indicates better quality of life [1-4].

\section{Hospitalisation}

Retrospective hospitalisation data were collected for year 2004. Among all the patients, 757 patients had complete data and were enrolled for the hospitalisation analysis, but only 309 patients of them were defined hospitalisation, the other were defined non-hospitalisation for access-related hospitalisation (HD patients artery-venous fistula operation, PD catheter implantation) and transplanted-related hospitalisation were excluded. Hospital admissions for a variety of disorders were analyzed [12].

\section{Statistical analysis}

Demographic and clinical data were described as mean \pm SD for continuous variables. The differences in demographic data and SF-36 scores between PD and HD groups were analyzed by independent $t$ tests for normally distributed variables or nonparametric tests for non-normally distributed variables. The effects of age, gender, diabetic status and Charlson index were adjusted by covariate analysis. To perform covariate analysis, the logarithmically transformed SF-36 scores were treated as dependent variables, while the modality of dialysis was treated as a fixed factor and the age, gender, diabetic status and Charl-

Table I: Demographic data of the dialysis patients

\begin{tabular}{|c|c|c|c|c|}
\hline & $\mathrm{HD}(\mathrm{N}=654)$ & Percentage & $\mathrm{PD}(\mathrm{N}=408)$ & Percentage \\
\hline \multicolumn{5}{|l|}{ Characteristic } \\
\hline \multicolumn{5}{|l|}{ Age } \\
\hline$<40$ & 51 & $7.7 \%$ & 26 & $6.3 \%$ \\
\hline $40-49$ & 135 & $20.6 \%$ & 34 & $8.3 \%$ \\
\hline $50-59$ & 167 & $25.5 \%$ & 111 & $27.2 \%$ \\
\hline $60-69$ & 195 & $29.8 \%$ & 121 & $29.7 \%$ \\
\hline $70-79$ & 94 & $14.4 \%$ & 96 & $23.5 \%$ \\
\hline $80+$ & 12 & $1.8 \%$ & 20 & $4.9 \%$ \\
\hline Age(mean) & $57.22 \pm 12.49$ & & $61.59 \pm 12.65$ & \\
\hline \multicolumn{5}{|l|}{ Gender } \\
\hline$\%$ female & 294 & $45.0 \%$ & 243 & $59.6 \%$ \\
\hline \multicolumn{5}{|l|}{ Employment } \\
\hline Employed & 20 & $3.0 \%$ & 30 & $7.4 \%$ \\
\hline \multicolumn{5}{|l|}{ Marital status } \\
\hline \%current married & 609 & $93.11 \%$ & 390 & $95.58 \%$ \\
\hline Charlson comorbidity Index & $4.78 \pm 1.06$ & & $4.30 \pm 0.58$ & \\
\hline \multicolumn{5}{|l|}{ Cause of ESRD } \\
\hline Glomerulonephritis & 301 & $46.0 \%$ & 195 & $47.8 \%$ \\
\hline Hypertensive nephropathy & 110 & $16.8 \%$ & 63 & $15.4 \%$ \\
\hline Diabetic nephropathy & 99 & $15.1 \%$ & 42 & $10.2 \%$ \\
\hline Drug-induced renal lesion & 88 & $13.5 \%$ & 39 & $9.6 \%$ \\
\hline Unknown cause & 45 & $6.9 \%$ & 53 & $13.0 \%$ \\
\hline Others & 9 & $3.2 \%$ & 16 & $4.0 \%$ \\
\hline
\end{tabular}

Abbreviations: ESRD, end-stage renal disease. 
Table 2: Comparison of SF-36 scores between PD and HD patients.

\begin{tabular}{|c|c|c|c|c|}
\hline SF-36 Domain & $\mathrm{HD}(\mathrm{n}=654)$ & $\mathrm{PD}(\mathrm{n}=408)$ & Unadjusted $\mathrm{P}$ & Adjusted $\mathrm{P}$ \\
\hline PF & $45.07 \pm 30.86$ & $49.88 \pm 30.63$ & 0.065 & 0.098 \\
\hline RP & $22.36 \pm 45.61$ & $26.41 \pm 48.05$ & 0.109 & 0.176 \\
\hline $\mathrm{BP}$ & $43.02 \pm 22.92$ & $52.16 \pm 26.21$ & 0.000 & 0.000 \\
\hline $\mathrm{GH}$ & $27.65 \pm 18.82$ & $36.75 \pm 21.72$ & 0.000 & 0.000 \\
\hline RE & $42.36 \pm 47.94$ & $57.65 \pm 48.06$ & 0.000 & 0.000 \\
\hline SF & $48.89 \pm 25.20$ & $56.71 \pm 25.02$ & 0.000 & 0.001 \\
\hline VT & $36.67 \pm 22.58$ & $45.40 \pm 24.30$ & 0.000 & 0.006 \\
\hline $\mathrm{MH}$ & $58.77 \pm 23.56$ & $68.08 \pm 21.83$ & 0.000 & 0.009 \\
\hline
\end{tabular}

Abbreviations: PF, Physical Functioning; RP, Role-Physical; BP, Body Pain; GH, General Health; RE, Role-Emotional; SF, Social Functioning; VT, Vitality; MH, Mental Health.

son index as covariates. $\mathrm{P}<0.05$ was considered as statistically significant. Statistical analyses were performed using SPSS 11.0 version.

\section{Results}

\section{Characteristics of the studied dialysis patients}

Of the 1073 patients enrolled in the study, 1062 completed the SF-36 questionnaire $(98.9 \%$ of responding rate). Table 1 showed relevant socio-demographic and clinical characteristics of the 1062 respondents. The results showed that the PD patients were elder than the hemodialysis patients $(\mathrm{P}=0.000)$, and there were more female patients in PD patients than that in hemodialysis patients $(59.6 \%$ vs. $45.0 \%, P=0.000)$. Less than $10 \%$ of dialysis patients were employed (HD 3.0\% vs. PD 7.4\%, P $=0.219$ ). The PD patients had lower Charlson index than HD patients $(4.30 \pm 0.58$ vs. $4.78 \pm 1.06, \mathrm{P}=0.000)$. The causes of ESRD were glomerlulonephritis (HD $46.0 \%$ and PD 47.8\%), hypertensive nephropathy (HD 16.8\% and PD $15.4 \%)$, diabetic nephropathy (15.1\% in HD vs. $10.2 \%$ in $\mathrm{PD}, \mathrm{P}=0.024$ ), drug-induced renal damage (HD $13.5 \%$ and $\mathrm{PD} 9.6 \%)$.

\section{Comparisons of quality of life}

The average scores for SF-36 domains of BP, GH, RE, SF, VT and MH were higher in PD patients than those in HD patients except PF and RP. This difference was still significant even after adjustment of age, gender, diabetic status and Charlson index by covariate analysis (Table 2). However, there were no significant differences between the diabetic patients and non-diabetic patients in terms of physical health and health dimensions, neither between the female and male patients (Table 3 and Table 4).

3. Analysis of the causes of hospitalisation in dialysis patients HD patients had higher hospitalisation as compared to PD patients (47.8\%vs 29.7\%, $\mathrm{P}=0.000)$. In HD patients, the two most common causes of hospitalisation were cardiovascular diseases and infection (especially pulmonary infection), while they were infection (especially infectious peritonitis) and cardiovascular diseases in PD patients (Table 5).

\section{The comparison of SF-36 domains between hospitalised and non-hospitalised dialysis patients}

Among the two major domains of the SF-36, the physical health dimension scores were also statistically different between the hospitalised patients and non-hospitalised patients, and the ever hospitalised patients had significant lower SF-36 domain scores (containing PF, BP, GH, RE, $\mathrm{SF}, \mathrm{VT}, \mathrm{MH}$, see in Table 6).

Table 3: Comparison of quality of life between gender groups.

\begin{tabular}{|c|c|c|c|}
\hline SF36 domain & Male $(n=525)$ & Female $(n=537)$ & $P$ \\
\hline PF & $45.17 \pm 30.17$ & $46.90 \pm 30.29$ & 0.398 \\
\hline $\mathrm{RP}$ & $23.76 \pm 43.72$ & $25.56 \pm 44.46$ & 0.182 \\
\hline $\mathrm{BP}$ & $43.58 \pm 23.93$ & $45.83 \pm 27.64$ & 0.156 \\
\hline $\mathrm{GH}$ & $30.40 \pm 19.98$ & $32.17 \pm 21.01$ & 0.215 \\
\hline RE & $47.94 \pm 48.32$ & $48.48 \pm 48.80$ & 0.877 \\
\hline SF & $51.19 \pm 22.57$ & $53.56 \pm 26.28$ & 0.069 \\
\hline VT & $39.71 \pm 23.56$ & $40.4 I \pm 23.74$ & 0.098 \\
\hline $\mathrm{MH}$ & $62.68 \pm 23.71$ & $63.01 \pm 23.08$ & 0.433 \\
\hline
\end{tabular}

Abbreviations: PF, Physical Functioning; RP, Role-Physical; BP, Body Pain; GH, General Health; RE, Role-Emotional; SF, Social Functioning; VT, Vitality; MH, Mental Health. 
Table 4: Comparison of quality of life between diabetic and non-diabetic patients

\begin{tabular}{|c|c|c|c|}
\hline SF-36 domain & Non-diabetic $(\mathrm{n}=92 \mathrm{I})$ & Diabetic $(n=|4|)$ & $P$ \\
\hline PF & $50.45 \pm 28.09$ & $44.19 \pm 30.96$ & 0.134 \\
\hline RP & $28.37 \pm 46.60$ & $23.24 \pm 46.57$ & 0.117 \\
\hline BP & $46.16 \pm 24.72$ & $49.10 \pm 24.31$ & 0.313 \\
\hline $\mathrm{GH}$ & $31.17 \pm 19.54$ & $31.15 \pm 20.60$ & 0.846 \\
\hline $\mathrm{RE}$ & $49.72 \pm 47.16$ & $47.93 \pm 48.76$ & 0.792 \\
\hline SF & $52.74 \pm 26.05$ & $51.76 \pm 25.32$ & 0.598 \\
\hline VT & $42.13 \pm 24.83$ & $39.71 \pm 28.43$ & 0.269 \\
\hline $\mathrm{MH}$ & $62.16 \pm 21.65$ & $62.38 \pm 28.63$ & 0.846 \\
\hline
\end{tabular}

Abbreviations: PF, Physical Functioning; RP, Role-Physical; BP, Body Pain; GH, General Health; RE, Role-Emotional; SF, Social Functioning; VT, Vitality; MH, Mental Health.

\section{Discussion}

Previous study reported that there was no simple answer to the question of which dialysis modality could be expected to provide better quality of life $[9,10]$. Several studies suggested advantages for PD in some domains $[11,12]$, and HD in others [3] or little difference between the two modalities[13,15].

The current study performed in China showed that PD patients reported better quality of life in mental health dimensions, GH (Combined mental health dimensions and physical health dimensions) and BP of physical health dimensions than HD patients except PF and RP if non-matched demographic data were not adjusted. This difference remained significant after adjustment of the patients' characteristics. It was interesting that we failed to demonstrate that diabetic status affected QOL, which was contrasted to some studies [2], but consisted with our previous investigations [14]. The exact cause for better QOL in Chinese PD patients is not clearly at present, but we believe that the following reasons should be considered. Firstly, the lower body mass index in Chinese patients may be translated as an adequate dialysis could be achieved with a relatively lower dialysis dose. Indeed, there are reports that the survival in Hong Kong Chinese PD patients is better than that in Caucasian patients in Western world, although the former have relatively lower $\mathrm{Kt} / \mathrm{V}$ [16]. Secondly, it is reported that the micro-inflam- mation state, a predictor of cardiovascular event in dialysis patients [17], is lower in Asian patients than that in Western patients [18], which may be due to the difference in race and/or dietary habits.

Our current study also showed that the RP score in Chinese dialysis patients was low, consisting with the low employment rate (HD 3.2\%, PD 7\%) observed in this study. This might be due to the following reasons: Firstly, many Chinese patients do not accept the concept of timely dialysis until they suffer more and severer comorbidity; Secondly, the Chinese dialysis patients usually depend on the care of their family members (their children, spouse, sisters and brothers, parents, etc); Thirdly, Chinese dialysis patients are often not re-employed because of their end stage renal disease.

The current study showed that the cause of hospitalisation differed between PD and HD. In our HD patients, cardiovascular disease was most common cause and infection ranked the second. Moreover, majority of cause of hospitalisation were congestive heart failure in HD patients. Our results were consisted with some previous reports. Rayner [19] reported that cardiac disease was a common cause of death in chronic hemodialysis patients. A subanalysis of the data on cardiac diseases in the Hemodialysis (HEMO) Study by Cheung[20] found that among the total of 1685 cardiac hospitalisations, angina and acute

Table 5: Cause of hospitalisation for dialysis patients (number of patients)

\begin{tabular}{lll}
\hline Cause of hospitalisation & HD & PD \\
\hline Infection-related & $47^{* \#}$ & $41^{* \#}$ \\
Cardiovascular disease & $89^{* \#}$ & $30^{*} \#$ \\
Hemorrhage & 21 & \\
Vascular access & 34 & 7 \\
PD technique problem & & 8 \\
Others & 32 & $86 \#$ \\
Total & 223 &
\end{tabular}

$* \mathrm{P}<0.01$ Compared with within $\mathrm{HD}$ and $\mathrm{PD}$ patients by Chi-square test

$\# \mathrm{P}<0.0$ I Compared between HD and PD patients by Chi-square test 
Table 6: Comparison of SF 36 domains between hospitalisation and non-hospitalisation patients.

\begin{tabular}{llll}
\hline SF 36 domain & Hospitalisation $N=309$ & Non-hospitalisation $N=448$ & $P$ \\
\hline PF & $41.35 \pm 18.00$ & $46.01 \pm 19.02$ & 0.03 \\
RP & $22.57 \pm 42.52$ & $24.94 \pm 44.48$ & 0.179 \\
BP & $42.66 \pm 21.22$ & $46.67 \pm 22.34$ & 0.009 \\
GH & $26.64 \pm 20.32$ & $32.89 \pm 20.44$ & 0.01 \\
RE & $41.89 \pm 48.12$ & $52.20 \pm 49.28$ & 0.001 \\
SF & $49.67 \pm 26.17$ & $53.69 \pm 23.62$ & 0.001 \\
VT & $38.85 \pm 22.41$ & $40.61 \pm 20.25$ & 0.03 \\
MH & $63.43 \pm 23.68$ & $64.18 \pm 23.32$ & 0.03
\end{tabular}

Abbreviations: PF, Physical Functioning; RP, Role-Physical ; BP, Body Pain ; GH, General Health; RE, Role-Emotional ; SF, Social Functioning; VT, Vitality; MH, Mental Health.

myocardial infarction accounted for $42.7 \%$ of all the hospitalisations. Allon M[21] reported infectious complication was common in hemodialysis patients and the frequency of a severe outcome varied greatly by infectious disease category, being highest for cardiac infections (95.6\%) and infection of unknown source (68.4\%), and lowest for urinary tract infections $(35.5 \%)$ and accessrelated infections $(43.8 \%)$.

For PD patients, although majority of Chinese PD patients have been using twin-bag system of Baxter Ltd since late 1990 's, infectious disease especially peritonitis remained to be the most common cause of hospitalisation in our patients indicating further efforts are need to decreased the incidence of peritonitis in this patient population.

Kalantar[22] reported that prospective hospitalisations of hemodialysis patients correlated significantly with the SF36 total score and its two main dimensions. Our retrospective hospitalised patients had worse quality of life than non-hospitalised patients, decreasing cormorbidities should thus be an effective way to improve the quality of life in dialysis patients.

In conclusion, although the present study is not a randomized controlled study and the selection of dialysis modality may have been biased in many aspects, our study indicated that with the current practice in China, PD patients may enjoyed better quality of life than their HD counterparts. Our results also showed that the most common cause of hospitalisation was cardiovascular disease in HD patients and peritonitis in PD patients.

\section{Acknowledgements}

This work was supported by Baxter LTD (China) and the Chinese Society of Medical Insurance.

The following people and hospitals have participated in the study and are greatly appreciated. Ping Zhu and Ai -Wu Lin from Division of Nephrology, Shanghai Second Medical University Ruijin Hospital and Renji Hospital, Shanghai, P.R. China; Zhang-Suo Liu from Division of Nephrology, Zhengzhou University First hospital, Zhengzhou, P.R. China; Jian Yao from
Division of Nephrology, Shanghai First Hospital, Shanghai, P.R. China; QunYing Guo from Division of Nephrology, Sun Yat-Sen University affiliated First Hospital, Guangzhou, P.R. China; Wen- Hu liu Division of Nephrology, Beijing Friendship Hospital, Beijing, P.R. China; Xin-Zhou Zhang from Division of Nephrology, Shenzhen First Hospital, Shenzhen, P.R. China and FUYou Liu from Division of Nephrology, Zhongnan University Second Hospital, Changsha, P.R. China.

\section{References}

I. Diaz-Buxo JA, Lowrie EG, Lew NL, Zhang H, Lazarus JM: Quality-oflife evaluation using Short Form 36: comparison in hemodialysis and peritoneal dialysis patients. American Journal of Kidney Disease 2000, 35:293-300.

2. Mingardi G, Cornalba L, Cortinovis E, Ruggiata R, Mosconi P, Apolone G: Health-related quality of life in dialysis patients. A report from an Italian study using the SF-36 Health Survey. DIAQOL Group. Nephrology Dialysis Transplantation 1999, I4:|503-I5I0.

3. Meyer KB, Espindle DM, DeGiacomo JM, Jenuleson CS, Kurtin PS, Davies AR: Monitoring dialysis patients' health status. American Journal of Kidney Disease 1994, 24:267-279.

4. De Oreo PB: Hemodialysis patient-assessed functional health status predicts continued survival, hospitalisation, and dialysis-attendance compliance. American Journal of Kidney Disease 1997, 30:204-212.

5. Hlatky MA: Comorbidity and outcome in patients with coronary artery disease. Journal of American College of cardiology 2004, 43:583-584.

6. Charlson ME, Pompei P, Ales KL, MacKenzie CR: A new method of classifying prognostic comorbidity in longitudinal studies: development and validation. Journal Chronic Disease 1987, 40:373-383.

7. Fried L, Bernardini J, Piraino B: Charlson comorbidity index as a predictor of outcomes in incident peritoneal dialysis patients. American Journal of Kidney Disease 200I, 37:337-342.

8. Miskulin DC, Martin AA, Brown R, Fink NE, Coresh J, Powe NR, Zager PG, Meyer KB, Levey AS: Predicting I year mortality in an outpatient haemodialysis population: a comparison of comorbidity instruments. Nephrology Dialysis Transplantation 2004, 19:413-420.

9. Marti F, Catherine H, Duboies MF: Comparative assessment of three different indices of multimorbidity for studies on health-related quality of life. Health and Quality of Life Outcomes 2005, 3:74-77.

10. Walters BA, Hays RD, Spritzer KL, Fridman M, Carter WB: Healthrelated quality of life, depressive symptoms, anemia, and malnutrition at hemodialysis initiation. American Journal of Kidney Disease 2002, 40: I 185- I 194.

II. Wasserfallen JB, Halabi G, Saudan P, Perneger T, Feldman HI, Martin PY, Wauters JP: Quality of life on chronic dialysis: comparison between hemodialysis and peritoneal dialysis. Nephrology Dialysis Transplantation 2004, 19:1594-1599.

12. Wu AW, Fink NE, Jane VR: Changes in Quality of Life during Hemodialysis and Peritoneal Dialysis Treatment: Generic 
and Disease Specific Measures. Journal of the American Society Nephrology 2004, 15:743-753.

13. Merkus MP, Jager KJ, Dekker FW, De Haan RJ, Boeschoten EW, Krediet RT: Quality of life over time in dialysis: The Netherlands Cooperative Study on the Adequacy of Dialysis. NECOSAD Study Group. Kidney International 1999, 56:720-728.

14. Tang Wen, Li-tao Cheng, Wang Tao : Diabetic Patients Can Do as Well on Peritoneal Dialysis as Non-diabetic Patients. Blood Purification 2005, 23:330-337.

15. Manns B, Johnson JA, Taub K: Quality of life in patients treated with hemodialysis or peritoneal dialysis: what are the important determinants? Clinical Nephrology 2003, 60:34I-35I.

16. Li Phillp KT, Szeto Cheuk-chun : Adequacy targets of peritoneal dialysis in the Asian population. Peritoneal Dialysis International 200I:S378-S383.

17. Stenvinkel P, Wanner C, Metzger T, Heimbürger O, Mallamaci F, Tripepi G, Malatino L, Zoccali C: Inflammation and outcome in end-stage renal failure: Does female gender constitute a survival advantage? Kidney International 2002, 62:179I-I 798.

18. Noh H, Lee SW, Kang SW: Serum C-reactive protein: A predictor of mortality in continuous ambulatory peritoneal dialysis patients. Peritoneal Dialysis International 1998, 1 8:387-394.

19. Rayner HC, Pisoni RL, Bommer I: Mortality and hospitalisation in haemodialysis patients in five European countries: results from the Dialysis Outcomes and Practice Patterns Study (DOPPS). Nephrology Dialysis Transplantation 2004, 19:108-I 20.

20. Cheung AK, Sarnak MJ, Yan G, Berkoben M, Heyka R, Kaufman A, Lewis J, Rocco M, Toto R, Windus D, Ornt D, Levey AS: Cardiac diseases in maintenance hemodialysis patients: results of the HEMO Study. Kidney International 2004, 65:2380-2389.

21. Allon M, Radeva M, Bailey J, Beddhu S, Butterly D, Coyne DW, Depner TA, Gassman JJ, Kaufman AM, Kaysen GA, Lewis JA, Schwab SJ: The spectrum of infection-related morbidity in hospitalised haemodialysis patients. Nephrology Dialysis Transplantation 2005 , 20: II80-1186.

22. Kalantar-Zadeh K, Kopple JD, Block G, Humphreys MH: Association Among SF36 Quality of Life Measures and Nutrition, Hospitalisation, and Mortality in Hemodialysis. Journal of the American Society Nephrology 200 I, I 2:2797-2806.

\section{Publish with Bio Med Central and every scientist can read your work free of charge}

"BioMed Central will be the most significant development for disseminating the results of biomedical research in our lifetime. "

Sir Paul Nurse, Cancer Research UK

Your research papers will be:

- available free of charge to the entire biomedical community

- peer reviewed and published immediately upon acceptance

- cited in PubMed and archived on PubMed Central

- yours - you keep the copyright
BioMedcentral 